\title{
Quality of maternity care provided by private sector healthcare facilities in three states of India: a situational analysis
}

Sanjay Tripathi', Ashish Srivastava ${ }^{2 *}$ D, Parvez Memon ${ }^{1}$, Tapas Sadasivan Nair ${ }^{2}$, Parag Bhamare ${ }^{3}$, Dinesh Singh $^{4}$ and Vineet Srivastava ${ }^{2}$

\begin{abstract}
Background: Better quality of care around the time of childbirth can significantly improve maternal and newborn survival. In countries like India, where the private sector contributes to a considerable proportion of institutional deliveries, it is important to assess the quality of maternity care offered by private sector healthcare facilities. This study seeks to fill that information gap by analysing baseline assessments conducted for the Manyata program, which aims to improve the quality of maternity care at private facilities.

Methods: An observation checklist based on 16 clinical standards endorsed by the Federation of Obstetric and Gynaecological Societies of India (FOGSI) was used to assess 201 private sector healthcare facilities in Maharashtra, Jharkhand, and Uttar Pradesh. Data on facility characteristics came from profiles completed when facilities enrolled in Manyata. Differences in the mean number of standards met were analysed by facility characteristics and the availability of essential supplies.

Results: Around half (47.1\%) of all nursing staff engaged in maternity care services at these private healthcare facilities were under qualified. The mean number of clinical standards met by facilities was 3.2 (SD 2.4). Facilities with a monthly delivery load between 20 and 50 met a significantly higher number of standards, as did facilities that had more than $70 \%$ of essential supplies available. Both these factors were also significant in a multiple linear regression analysis.
\end{abstract}

Conclusions: The overall quality of maternity care in private healthcare facilities is poor in all three states, especially for clinical standards related to management of complications.

Keywords: Quality of care, Facility preparedness, Private sector, Intrapartum care, Postpartum care, Maternal health, Quality improvement

\section{Background}

Improving quality of care is essential to ensure patient safety and accelerate reductions in mortality and morbidity [1]. To prevent avoidable maternal and neonatal deaths, every pregnant woman and newborn baby needs skilled care at the time of birth, with evidence-based clinical and non-clinical interventions delivered in a compassionate and enabling environment [2,3]. Global

\footnotetext{
* Correspondence: asheishsrivastava@gmail.com;

Ashish.Srivastava1@Jhpiego.org

${ }^{2}$ Jhpiego - an affiliate of Johns Hopkins University, Jhpiego, 29, Okhla Phase

3, New Delhi, India

Full list of author information is available at the end of the article
}

evidence has proven that better quality of care at childbirth could avert up to 1.49 million maternal and newborn deaths and stillbirths annually and significantly improve maternal and newborn survival $[4,5]$. The majority of maternal deaths (over 70\%) result from complications that require facility-based care, such as postpartum hemorrhage, hypertensive disorders, sepsis, and complications related to abortions [6]. Therefore, improving the quality of facility-based delivery care offers tremendous opportunities to reduce maternal and perinatal deaths [7].

In India, after the launch of government's conditional cash transfer scheme for promoting institutional

(c) The Author(s). 2019 Open Access This article is distributed under the terms of the Creative Commons Attribution 4.0 International License (http://creativecommons.org/licenses/by/4.0/), which permits unrestricted use, distribution, and reproduction in any medium, provided you give appropriate credit to the original author(s) and the source, provide a link to the Creative Commons license, and indicate if changes were made. The Creative Commons Public Domain Dedication waiver (http://creativecommons.org/publicdomain/zero/1.0/) applies to the data made available in this article, unless otherwise stated. 
deliveries, the Janani Suraksha Yojana (JSY), rate of institutional deliveries has nearly doubled over the last decade [8]. However, the significant gains achieved in maternal and neonatal mortality were not sufficient to help the country achieve Millennium Development Goals 3 and 4 [9]. Therefore in the context of Sustainable Development Goal 3 [10], it is essential to focus on the provision of high quality care during childbirth to reduce adverse maternal and neonatal outcomes [11, 12]. This requires a focus on private as well as public sector healthcare facilities. The private sector contributes to a considerable proportion of institutional deliveries across the world [13] and plays an important role in delivering health care services in India, providing $80 \%$ of all outpatient care and up to $60 \%$ of inpatient care. As many as $60 \%$ of hospital beds in India are in the private sector, as are the majority of human resources, including $70 \%$ of the total health workforce, $80 \%$ of physicians, and most obstetricians [14]. According to the National Family Health Survey 4 (NFHS-4), the private sector accounts for up to $22 \%$ of institutional deliveries in rural areas and up to $43 \%$ of institutional deliveries in urban areas [15].

Although the Government of India has introduced several initiatives targeting various aspects of quality in service delivery and facility operations of public sector health facilities [16-18], the private sector has not received much attention. The bulk of available research evidence on the quality of essential care at the time of birth - mostly from public sector facilities in low- and middle-income countries (LMICs) - highlights the need to carefully examine and address deficiencies in the quality of care at the time of birth. However, research on the quality of maternity care in private healthcare facilities in India is limited [19]. In this context, it becomes important to understand the landscape of quality of maternity care in the private sector, make a systematic effort to measure, and identify quality gaps.

The Manyata program is a quality improvement and assurance initiative for private sector maternity care facilities across three states (Uttar Pradesh, Jharkhand, and Maharashtra) [20]. Facilities, which voluntarily opt, to participate in the program receive three days nurses training on skills and competencies related to key lifesaving practices and six deliverable linked mentoring support visits for six months period. Program also ascertains the quality of maternity care, once the facility completes its quality improvement journey and achieves a set number of standards at the final assessment to obtain Manyata certification, which is a seal of quality assurance. The program is being implemented by Jhpiego, an affiliate of Johns Hopkins University, with support from MSD for Mothers and in collaboration with the Federation of Obstetric and Gynecological Societies of India (FOGSI). Baseline assessments conducted under
Manyata program provided an opportunity to measure the existing quality of care at childbirth in participating private healthcare facilities. This paper is a retrospective examination of the baseline data intended to yield insights on the quality of delivery care practices at private healthcare facilities in three states of India.

\section{Methods}

\section{Study settings, study design and sampling}

A structured checklist was used to assess 201 private sector healthcare facilities that offer obstetric care in 24 districts across the states of Maharashtra, Jharkhand and Uttar Pradesh. Uttar Pradesh is the most populous state in India with a population of 199 million. Maharashtra and Jharkhand are 2nd and 13th most populous states in India (out of 28 states) with a population of 112 million and 33 million respectively [21]. With respect to performance on maternal health, while Uttar Pradesh and Jharkhand are poor performing states with maternal mortality ratio (MMR) of 165 and 201 respectively, Maharashtra is a better performing state with MMR of 61 [22].

Baseline assessments for the Manyata program at these facilities were conducted from November 2016 to March 2017 (year 1 facilities) and from December 2017 to March 2018 (year 2 facilities). The criteria for including private healthcare facilities in the Manyata program are that the facility: 1) is registered with local health authorities, 2) provides maternity services, 3) has an owner or in-charge who is a member of FOGSI, and 4) expresses willingness to participate in the Manyata program by paying a nominal fee and submitting letter of intent to FOGSI.

\section{Study tool}

The assessment checklist was based on the standards for improving quality of maternal and newborn care in health facilities by WHO and endorsed by FOGSI [23, 24]. It includes 16 clinical standards that focus on: patient care during the antenatal period (one standard), the intrapartum period (13 standards), the postpartum period (one standard), and caesarean section (one standard). Each standard includes four or five essential elements and has five or six verification criteria, which ensure the objective assessment of providers' skills and knowledge (Fig. 1).

Assessors recorded "Y" for each verification criterion that the provider or facility met and "N" for unmet criteria. If all of the verification criteria listed under a standard were met, the standard was considered as met and given a score of 1 . If any verification criteria were not met, the entire standard was considered unmet and given a score of zero. The facility score was calculated as the total number of standards met; the highest possible score was 16 . 


\begin{tabular}{|r|l|}
\hline SN. & \\
\hline $\mathbf{1}$ & Provider screens for key clinical conditions that may lead to complications during \\
\hline $\mathbf{2}$ & Pregnancy (to be verified only among booked cases) \\
\hline $\mathbf{3}$ & Provider assesses all pregnant women at admission \\
\hline $\mathbf{4}$ & Providers conducts Per-Vaginum (PV) examination appropriately \\
\hline $\mathbf{5}$ & Provider monitors the progress of labor appropriately \\
\hline $\mathbf{6}$ & Provider ensures respectful and supportive care \\
\hline $\mathbf{7}$ & Provider assists the pregnant woman to have a safe and clean birth \\
\hline $\mathbf{8}$ & Provider conducts a rapid initial assessment and performs immediate newborn care \\
\hline $\mathbf{1 6}$ & Provider reviews clinical practices related to caesarean section at regular intervals \\
\hline $\mathbf{9}$ & Provider performs Active Management of Third Stage of Labor (AMTSL) \\
\hline $\mathbf{1 0}$ & Provider identifies and manages postpartum hemorrhage (PPH) \\
\hline $\mathbf{1 1}$ & Provider identifies and manages severe pre-eclampsia/eclampsia (PE/E) \\
\hline $\mathbf{1 2}$ & Provider performs newborn resuscitation if baby does not cry immediately after \\
\hline $\mathbf{1 3}$ & Provider ensures care of newborn with small size at birth \\
\hline birth
\end{tabular}

Fig. 1 FOGSI Clinical Standards for Manyata Program

\section{Data collection}

Manyata Program Officers, who were either nursing professionals or doctors, conducted the baseline assessments. They were oriented and trained on the assessment methodology and technical components of the standards as part of the program's Training of Trainers (ToT). These three-day ToTs were conducted by the program's clinical team, which consisted of senior obstetricians with public health experience. Assessments at each facility were usually spread across two days and required 4-6 working hours per day, using a mixed methods approach.

Each verification criterion was assessed using one of the following four methods: 1) direct observation of service providers during skills demonstration on mannequins or during provision of actual care; 2) hospital record reviews to check for the implementation of practices; 3) provider interviews to assess knowledge; or 4) physical verification of the presence of drugs, supplies, functional equipment, and instruments in the labor room. Verification criteria related to provider skills were assessed through observations, those related to provider knowledge were assessed through interviews, those related to routine practices at the facility were assessed through record reviews, and those related to availability of drugs and equipment were assessed through physical verification.

In addition, information on facility characteristics, such as facility type based on the availability of services, average monthly delivery load, availability of human resources, and number of hospital beds, were collected when the facility registered for the Manyata program. For availability of human resources, data on number of qualified nursing staff per facility was collected. Qualified nursing staff refers to those nursing personnel who have undergone formal training under any of the Indian Nursing Council prescribed programs [25].

\section{Data analysis}

For the purpose of this analysis, a separate dataset was created by combining the baseline assessment data with 
the facility characteristics data. Data were cleaned and checked for completeness. We computed the mean number of standards met by the facilities, the proportion of facilities that met each individual standard, and the proportion of facilities that met a set number of standards. We analyzed variations in the mean number of standards met by various facility characteristics and the availability of essential supplies. To identify determinants of the number of standards met by a facility, we conducted a multivariable linear regression analysis, with number of standards met by facilities as the dependent variable and facility characteristics and availability of essential supplies as independent variables. We used independent sample $t$ test and ANOVA for comparing means of two and three subgroups respectively. A $p$ value of less than 0.05 was considered as statistically significant. Statistical Package for the Social Sciences (SPSS), version 24, were used to carry out the data analysis.

\section{Results}

\section{Characteristics of facilities}

Two-thirds of the 201 private healthcare facilities enrolled in the Manyata program were from Uttar Pradesh and Jharkhand collectively (Table 1). A majority (87\%) were small health care providers with fewer than 50 functional beds. The average monthly delivery load for most facilities (59.7\%) was less than 20 deliveries. Most of the facilities (87\%) had at least one qualified nurse or midwife on staff, although almost half $(47.1 \%)$ of the

Table 1 Characteristics of private health care facilities $(n=201)$

\begin{tabular}{lll}
\hline Characteristics & Number & Percent \\
\hline State & 101 & 50.3 \\
Uttar Pradesh & 67 & 33.3 \\
Maharashtra & 33 & 16.4 \\
$\quad$ Jharkhand & & \\
Number of hospital beds & 184 & 91.5 \\
$\quad \leq 50$ & 17 & 8.5 \\
$>50$ & & 59.7 \\
Monthly delivery load & 120 & 30.8 \\
$\quad<20$ & 62 & 9.5 \\
20-50 & 19 & \\
$\quad$ 50 & & 55.7 \\
Type of facility & 112 & 44.3 \\
Exclusive maternity hospital & 89 & 12.9 \\
Multispecialty hospital & & 87.1 \\
Availability of qualified nurse or midwife & & \\
None on staff & 26 & \\
At least one on staff & 175 & \\
\hline
\end{tabular}

nursing staff at the facilities were under qualified (data not shown).

\section{Standards met}

The mean number of standards met by private health facilities across the three states was 3.2 (SD 2.4). Less than one-fourth $(24.4 \%)$ of the 201 private healthcare facilities met more than four standards (Table 2).

The standard most often met, by $65.2 \%$ of facilities, was assessing pregnant women at admission. Standards for newborn resuscitation and periodic review of clinical practices related to caesarean section were the least often met (3.5\%) (Fig. 2). Only 17\% of facilities met the standard for respectful and supportive care, mostly because facilities failed to allow a birth companion during labor.

The mean number of standards met varied across states, with Uttar Pradesh having the highest mean score (3.61) and Jharkhand the lowest (2.76), but this difference was not statistically significant. However, mean scores did vary significantly by monthly delivery load and availability of essential supplies. The mean number of standards met by facilities with 20-50 monthly deliveries was significantly higher than other facilities (4.14 versus 2.97 and 2.42). Facilities that had more than $70 \%$ of essential supplies also met significantly more standards than other facilities (4.54 versus 1.96) (Table 3).

\section{Determinants of number of standards met}

The multivariate linear regression analysis found that monthly delivery load and availability of essential supplies were significant determinants of the number of standards met by the private healthcare facilities. Facilities with a moderate delivery load (20-50 deliveries per month) and facilities with at least $70 \%$ of essential supplies available met a significantly more standards (Table 4).

\section{Discussion}

Overall, the quality of care around childbirth at private healthcare facilities was poor. Three-fourths of facilities enrolled in the Manyata program met only four or fewer of the 16 FOGSI-endorsed clinical standards; only one facility met more than 12 of the standards. This is similar to findings from the few other studies carried out in Uttar Pradesh

Table 2 Distribution of facilities according to number of standards met $(n=201)$

\begin{tabular}{lll}
\hline $\begin{array}{l}\text { Facility score } \\
\text { (number of standards met) }\end{array}$ & Number of facilities & Percent \\
\hline $0-4$ & 152 & 75.6 \\
$5-8$ & 41 & 20.4 \\
$9-12$ & 7 & 3.5 \\
$13-16$ & 1 & 0.5 \\
\hline
\end{tabular}




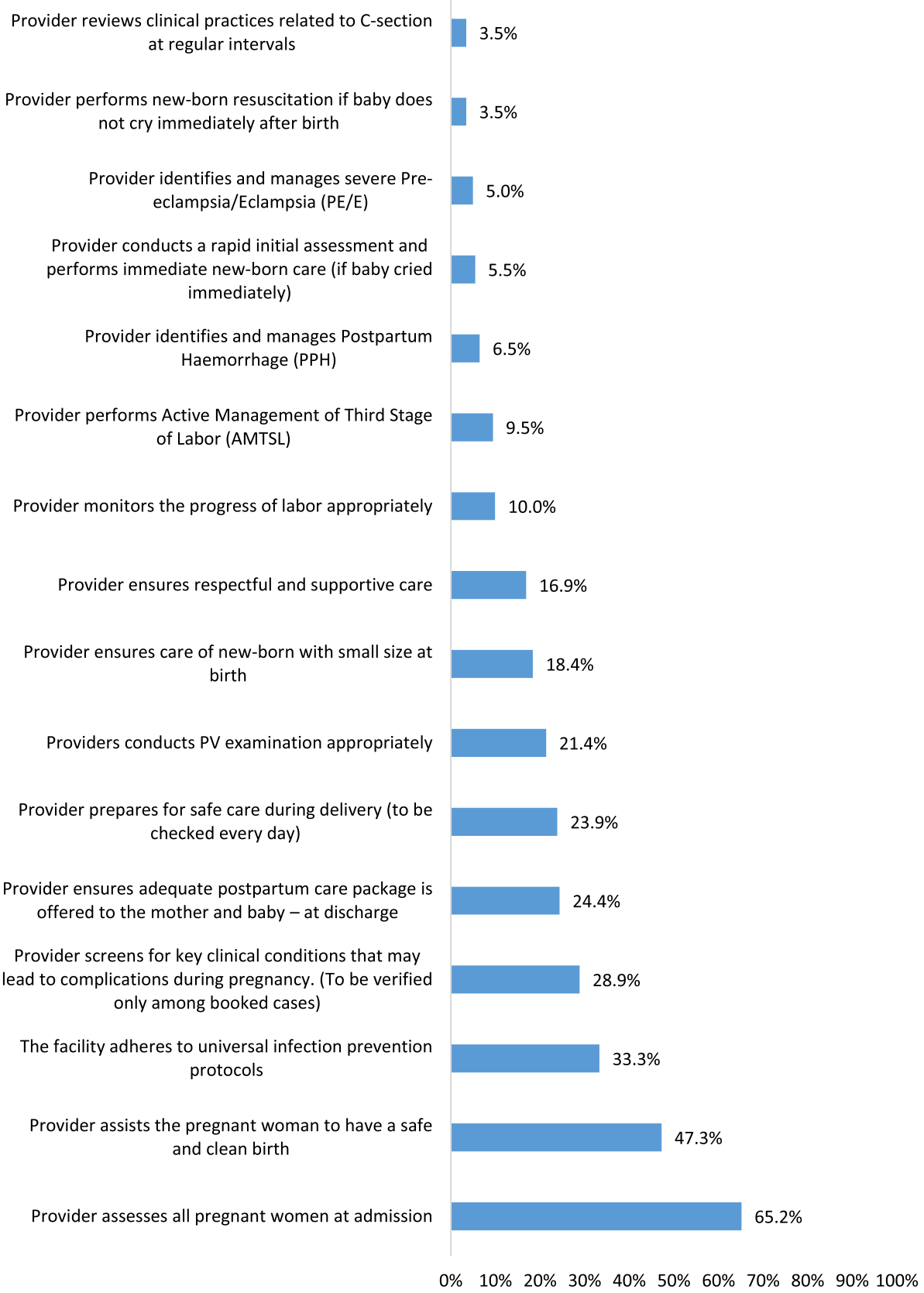

Fig. 2 Proportion of facilities that met each standard $(n=201)$

and Maharashtra that have evaluated the quality of care in private healthcare facilities [26-28]. However, the results are noteworthy as private health care facilities are generally perceived to be more efficient and provide better quality of services [29]. This is probably the reason why Indian families who can afford to pay prefer private sector services over the public health system, despite the added expense [30].

One reason why the quality of care may be so poor at these private sector healthcare facilities is the lack of qualified staff. We found that the mean number of standards met was higher at facilities with at least one qualified nurse or midwife on staff, although this difference was not statistically significant. Almost half of all nursing staff engaged in maternity care services at these private healthcare facilities were under qualified, and $13 \%$ of facilities did not have a single qualified nurse or midwife on staff. These findings are similar to a previous analysis by Rao et al [31], which estimated that $58.4 \%$ of nurses and midwives serving 
Table 3 Mean number of standards met, by facility characteristics $(n=201)$

\begin{tabular}{|c|c|c|}
\hline Characteristics & $\begin{array}{l}\text { Mean number of } \\
\text { standards met (SD) }\end{array}$ & $p$ value $^{\#}$ \\
\hline \multicolumn{3}{|l|}{ State } \\
\hline Uttar Pradesh & 3.61 (SD 3.3) & \multirow[t]{3}{*}{$P>0.05$} \\
\hline Maharashtra & $3.42(\mathrm{SD} 2.1)$ & \\
\hline Jharkhand & 2.76 (SD 2.2) & \\
\hline \multicolumn{3}{|l|}{ Number of hospital beds } \\
\hline$\leq 50$ & 3.26 (SD 2.4) & \multirow[t]{2}{*}{$P>0.05$} \\
\hline$>50$ & $2.94(S D 2.9)$ & \\
\hline \multicolumn{3}{|l|}{ Monthly delivery load } \\
\hline$<20$ & $2.97(\mathrm{SD} 2.1)$ & \multirow[t]{3}{*}{$P<0.05$} \\
\hline $20-50$ & $4.14(\mathrm{SD} 2.9)^{*}$ & \\
\hline$>50$ & $2.42(\mathrm{SD} 2.1)$ & \\
\hline \multicolumn{3}{|l|}{ Type of facility } \\
\hline Exclusive maternity hospital & $3.36(S D-2.4)$ & \multirow[t]{2}{*}{$P>0.05$} \\
\hline Multispecialty hospital & 3.07 (SD- 2.4) & \\
\hline \multicolumn{3}{|c|}{ Availability of qualified nurse or midwife } \\
\hline None staff & $2.92(\mathrm{SD} 1.4)$ & \multirow[t]{2}{*}{$P>0.05$} \\
\hline At least one on staff & 3.27 (SD 2.5) & \\
\hline \multicolumn{3}{|l|}{ Availability of essential supplies } \\
\hline$\leq 25$ items (70\% of supplies) & 1.96 (SD 1.6) & \multirow[t]{2}{*}{$P<0.05$} \\
\hline > 25 items (70\% of supplies) & 4.54 (SD 2.4) & \\
\hline
\end{tabular}

in the private healthcare facilities of India were under qualified. Likewise, a 2001 survey of private health care providers in Delhi [32] found that $41 \%$ were under qualified. In the absence of regulatory requirements for staffing, private facilities may employ unskilled staff to increase profit margins and compromise quality in the process [33].

Clinical care processes in private healthcare facilities in India are largely individually driven, as the government does not mandate the uniform use of standard care practices in the private sector. This heightens the importance of professional organizations like FOGSI in standardizing care practices, as they can play a critical role in reviewing and prescribing care protocols to members [34].

The baseline assessment found that standards related to the assessment of pregnant women on admission and assisting pregnant women to have a safe and clean birth were met by relatively more facilities, while standards related to managing complications - which are relatively rare - were met by very few facilities. This needs to be seen in the context of the assessment methodology,
Table 4 Multiple linear regression analysis on number of standards met by the facilities

\begin{tabular}{|c|c|c|}
\hline Variable & $\begin{array}{l}\text { Standardized } \\
\text { coefficient (S.E.) }\end{array}$ & $\begin{array}{l}95 \% \text { confidence } \\
\text { interval }\end{array}$ \\
\hline \multicolumn{3}{|l|}{ State } \\
\hline Jharkhand & \multicolumn{2}{|c|}{ Reference category } \\
\hline Maharashtra & $-0.44(0.48)$ & $-1.39-0.51$ \\
\hline Uttar Pradesh & $0.37(0.47)$ & $-0.55-1.30$ \\
\hline \multicolumn{3}{|l|}{ Type of facility } \\
\hline Multispecialty hospital & \multicolumn{2}{|c|}{ Reference category } \\
\hline $\begin{array}{l}\text { Exclusive maternity } \\
\text { hospital }\end{array}$ & $0.31(0.34)$ & $-0.37-0.99$ \\
\hline \multicolumn{3}{|l|}{ Number of hospital beds } \\
\hline$\leq 50$ & \multicolumn{2}{|c|}{ Reference category } \\
\hline$>50$ & $0.09(0.58)$ & $-1.05-1.24$ \\
\hline \multicolumn{3}{|l|}{ Monthly delivery load } \\
\hline$<20$ & \multicolumn{2}{|c|}{ Reference category } \\
\hline $20-50$ & $0.72(0.35)$ & $0.02-1.41^{*}$ \\
\hline$>50$ & $-0.24(0.54)$ & $-1.32-0.82$ \\
\hline \multicolumn{3}{|c|}{ Availability of essential supplies } \\
\hline $\begin{array}{l}\leq 25 \text { items ( } 70 \% \text { of } \\
\text { supplies) }\end{array}$ & \multicolumn{2}{|c|}{ Reference category } \\
\hline $\begin{array}{l}>25 \text { items ( } 70 \% \text { of } \\
\text { supplies) }\end{array}$ & $2.49(0.31)$ & $1.86-3.12^{*}$ \\
\hline \multicolumn{3}{|c|}{ Availability of qualified nurse or midwife } \\
\hline None on staff & \multicolumn{2}{|c|}{ Reference category } \\
\hline At least one on staff & $0.54(0.48)$ & $-0.41-1.51$ \\
\hline
\end{tabular}

which considered the facility team (clinician and nursing staff) as a unit of measurement in assessing adherence to standards of care. Nursing staff are fully involved in routine care and thus could demonstrate their capabilities during the assessment. However, management of complications is heavily dependent on specialists at the facilities with limited involvement of nursing staff. This may be why the team could not demonstrate adherence to standards on management of complications.

Notably, the standard for respectful and supportive care was met by just one in six private healthcare facilities. Respectful care is a key component of quality of care, and mistreatment and poor quality of clinical care are closely interlinked [35]. The poor adherence to respectful care further correlates with existing evidence in both high [36-40] and low income settings [41-43], but contradicts the widespread perception that private healthcare facilities are more likely to provide respectful and supportive care due to their customer service orientation and concerns that a negative reputation on this front could hamper their profits.

A deeper look into the data revealed that the main reason why facilities did not meet the standard for respectful 
and supportive care was because of their failure to allow a birth companion during labor, which was one of the verification criteria for this standard. This hesitation in allowing a companion in the labor room may stem from fear of interference. Also, it is likely that many providers are not aware of the benefits of this practice for maternity outcomes [44].

Delivery load was a significant determinant of quality of care in the multiple linear regression; facilities with a moderate delivery load, between 20 and 50 deliveries per month, met significantly more standards than facilities with either lower or higher delivery loads. This load may be optimal because it ensures that staff receive regular practice but, at the same time, are not overburdened. Patient load and time spent with each patient by private providers have a significant bearing on the quality of health care [44]. The other significant factor in the regression was the availability of at least $70 \%$ of the essential items required for carrying out recommended practices. This corroborates previous studies [42, 43] that have found adequate supplies and infrastructure are important determinants of the quality of care in private sector healthcare facilities.

Among the three states where the Manyata program has been implemented, Uttar Pradesh and Jharkhand perform more poorly than Maharashtra on social and health indicators. Uttar Pradesh and Jharkhand score considerably below the national average of 0.639 on the Human Development Index [45], while Maharashtra scores above the national average. In addition, the private sector's contribution to institutional deliveries is greater in Maharashtra (45.8\%) as compared to Uttar Pradesh (34.4\%) and Jharkhand (32.5\%) [46-48]. However, this assessment found that the quality of care in private healthcare facilities was poor across all three states and did not vary significantly between states. This is corroborated by existing literature on the quality of care in private healthcare facilities in states like Maharashtra that found poor standards of care in small private health care facilities [26].

\section{Strengths and limitations}

Our analysis is an important addition to the scarce literature on the quality of maternity care in the private healthcare facilities of India. The fact that the facilities assessed came from both higher (Maharashtra) and lower performing states (Uttar Pradesh and Jharkhand) in terms of key maternal health indicators is a major strength of this study. In addition, the assessment standards are based on WHO standards for improving quality of maternal and newborn care in health facilities and endorsed by FOGSI. Therefore, the findings will be comparable with future studies that use similar standards and approach. However, there are some limitations to the interpretation of the findings. The facilities included in the analysis had voluntarily opted to participate in the Manyata program, so the sample may not be truly representative of private healthcare facilities across the three states. Facilities voluntarily opting to participate in the Manyata program for getting Manyata certified may differ from general private health care facilities in terms of being more conscious about importance of quality parameters or standards. In addition, direct observations of providers' skills were an important component of the assessment methodology and therefore, the findings are liable to the Hawthorne effect [49] that is health service providers may have been conscious of being observed and therefore improved their practices.

\section{Conclusion}

To our knowledge, such an extensive situational analysis of the readiness of private sector healthcare facilities to provide good quality intrapartum and immediate postpartum care has not been done before in India. The Manyata program provided an opportunity to objectively measure the quality of maternity care in private sector healthcare facilities in terms of FOGSI-endorsed standards. This secondary analysis of program data is valuable to stakeholders across the public health community of India as well as in similar settings globally; these include government, policy makers, donors, and implementing organizations as well as the private sector healthcare facilities themselves.

Historically, health programs and policies have been designed mostly to address the needs of public sector health facilities, and it has been assumed that health care practices are better at private sector facilities. In contrast, this study places a spotlight on deficiencies in the quality of care at private healthcare facilities and provides important insights for building a common policy framework to ensure standardized care across both public and private sectors or for creating a policy specific to the private sector.

\footnotetext{
Abbreviations

AMTSL: Active management of third stage of labor; ANOVA: Analysis of variance; FOGSI: Federation of Obstetric and Gynaecological Societies of India; MSD: Merck Sharp and Dohme; NFHS: National Family Health Survey; PE/E: Pre-eclampsia/eclampsia; PV: Per vaginum; SD: Standard deviation; SPSS: Statistical Package for the Social Sciences; ToTs: Training of trainers; WHO: World Health Organization; LMIC: Low and Middle Income Country

\section{Acknowledgements}

We are most grateful and extend our sincere thanks to all people who participated in this study. We would like to thank our internal reviewer Adrienne Kols for critically reviewing the manuscript and providing her valuable inputs. We would also like to acknowledge Kshitiz Mohan Lal for his support in organizing the dataset for the study. We thank our funder for their continued support. The research in this publication was supported by funding from MSD through its MSD for Mothers programme. MSD had no role in the design, collection, analysis and interpretation of data, in writing of the manuscript, or in decision to submit the manuscript for publication. The content of this publication is solely the responsibility of the authors and
} 
does not represent the official views of MSD. MSD for Mothers is an initiative of Merck \& Co. Inc. Kenilworth, NJ, USA.

\section{Author's contribution}

ST, AS, VS, DS and TN contributed to the concept and design of the study. ST and AS were involved in study database creation, checking, and analysis, and ST, PM, AS, PB and TN helped draft the manuscript. ST and AS finalized the manuscript. VS will act as guarantor for the project. All authors had full access to all of the data (including statistical reports and tables) in the study and can take responsibility for the integrity of the data and the accuracy of the data analysis. All authors read and approved the final manuscript.

\section{Funding}

This program was developed and is being implemented in collaboration with MSD for Mothers, MSD's 10-year, \$500 million initiative to help create a world where no woman dies giving life. MSD for Mothers is an initiative of Merck \& Co., Inc., Kenilworth, NJ, USA. MSD had no role in the design, collection, analysis and interpretation of data, in writing of the manuscript, or in decision to submit the manuscript for publication. The content of this publication is solely the responsibility of the authors and does not represent the official views of MSD.

\section{Availability of data and materials}

Data are available from Jhpiego's internal institutional data access committee for researchers who meet the criteria for access to data. Corresponding author can be contacted for further communication.

\section{Ethics approval and consent to participate}

The Johns Hopkins School of Public Health Institutional Review Board (IRB) reviewed the activities and determined them to be not human subjects research and thus not requiring IRB oversight. (IRB No: 00009525).

\section{Consent for publication}

Not Applicable.

\section{Competing interests}

The authors declare that they have no competing interests.

\section{Author details}

'Jhpiego an affiliate of Johns Hopkins University, Lucknow, Uttar Pradesh, India. ${ }^{2}$ Jhpiego - an affiliate of Johns Hopkins University, Jhpiego, 29, Okhla Phase 3, New Delhi, India. ${ }^{3}$ Jhpiego - an affiliate of Johns Hopkins University, Mumbai, Maharashtra, India. ${ }^{4}$ Jhpiego - an affiliate of Johns Hopkins University, Ranchi, Jharkhand, India.

Received: 25 June 2019 Accepted: 26 November 2019

Published online: 16 December 2019

\section{References}

1. Devkota HR, Clarke A, Murray E, Groce N. Do experiences and perceptions about quality of care differ among social groups in Nepal? A study of maternal healthcare experiences of women with and without disabilities, and Dalit and non-Dalit women. PLoS One Internet. 2017:12(12) Available from: https://www.ncbi.nlm.nih.gov/pmc/articles/PMC5736179/,cited 2019 Feb 13.

2. Barker PM, Reid A, Schall MW. A framework for scaling up health interventions: lessons from large-scale improvement initiatives in Africa. Implement Sci. 2016 Jan 29;11(1):12.

3. Tunçalp Ö, Were W, MacLennan C, Oladapo O, Gülmezoglu A, Bahl R, et al. Quality of care for pregnant women and newborns the WHO vision. BJOG. 2015 Jul;122(8):1045-9.

4. Graham W, Woodd S, Byass P, Filippi V, Gon G, Virgo S, et al. Diversity and divergence: the dynamic burden of poor maternal health. Lancet. 2016 Oct; 388(10056):2164-75

5. Horton R. Offline: ensuring healthy lives after 2015. Lancet. 2013 Jun; 381(9882):1972.

6. Say L, Chou D, Gemmill A, Tunçalp Ö, Moller A-B, Daniels J, et al. Global causes of maternal death: a WHO systematic analysis. Lancet Glob Health. 2014 Jun;2(6):e323-33.
7. Gabrysch S, Simushi V, Campbell OMR. Availability and distribution of, and geographic access to emergency obstetric care in Zambia. Int J Gynaecol Obstet. 2011;114(2):174-9.

8. Joe W, Perkins JM, Kumar S, Rajpal S, Subramanian SV. Institutional delivery in India, 2004-14: unravelling the equity-enhancing contributions of the public sector. Health Policy Plan. 2018 Jun 1;33(5):645-53.

9. Millennium Development Goals (MDGs) Report Internet. 2013 . Available from: mdgs-report-2013.html cited 2019 Feb 13

10. Goal 3: Good health and well-being | UNDP [Internet]. [cited 2019 Mar 27]. Available from: https://www.undp.org/content/undp/en/home/sustainabledevelopment-goals/goal-3-good-health-and-well-being.html\#targets

11. Akachi Y, Kruk ME. Quality of care: measuring a neglected driver of improved health. Bull World Health Organ. 2017 Jun 1;95(6):465-72.

12. Census of India Website : SRS Statistical Report 2013 Internet 2019. Available from: http://www.censusindia.gov.in/vital_statistics/SRS Reports_2013.html

13. Basu S, Andrews J, Kishore S, Panjabi R, Stuckler D. Comparative Performance of Private and Public Healthcare Systems in Low- and MiddleIncome Countries: A Systematic Review. PLoS Med Internet. 2012 Jun;9(6) Available from: https://www.ncbi.n/m.nih.gov/pmc/articles/PMC3378609/19 [cited 2019 Feb 13]

14. Facilitators and barriers to participation of private sector health facilities in government-led schemes for maternity services in India: a qualitative study BMJ Open Internet 2019. Available from: https://bmjopen.bmj.com/content/ 7/6/e017092

15. National Family Health Survey (NFHS-4) 2015-16 International Institute for Population Sciences [Internet]. [cited 2019. Available from: http://rchiips.org/ nfhs/NFHS-4Reports/India.pdf

16. Kayakalp Swacchta Guidelines for Public Health Facilities | National Health Portal Of India [Internet] 2019. Available from: https://www.nhp.gov.in/ kayakalp-swacchta-guidelines-for-public-health-facilities_pg

17. National Quality Assurance Standards_Blue.pdf Internet. 2019. Available from: http://qi.nhsrcindia.org/sites/default/files/National\%20Quality\%2 OAssurance\%20Standards_Blue.pdf

18. LaQshya-Guidelines.pdf Internet 2019 Available from: http://nhm.gov.in/ New_Updates_2018/NHM_Components/RMNCH_MH_Guidelines/LaQshyaGuidelines.pdf

19. $\mathrm{WHO}$ Q Quality of routine essential care during childbirth: clinical observations of uncomplicated births in Uttar Pradesh, India Internet. WHO 2019. Available from: http://www.who.int/bulletin/volumes/95/6/16-179291/en/

20. Manyata [Internet]. [cited 2019 Nov 7]. Available from: https://www. manyataformothers.org/

21. List of states with Population, Sex Ratio and Literacy Census 2011 [Internet]. [cited 2019 Nov 7]. Available from: https://www.census2011.co.in/states.php

22. Maternal Mortality Ratio (MMR) (per 100000 live births) | NITI Aayog [Internet]. [cited 2019 Nov 7]. Available from: https://niti.gov.in/content/ maternal-mortality-ratio-mmr-100000-live-births

23. FOGSI-CLINICAL-STANDARDS-for-accreditation-to-ensure-SAFE-DELIVERY.pdf [Internet]. [cited 2018 Dec 16]. Available from: https://www.fogsi.org/wpcontent/uploads/2016/12/FOGSI-CLINICAL-STANDARDS-for-accreditation-toensure-SAFE-DELIVERY.pdf

24. Standards for improving quality of maternal and newborn care in Health Facilities, WHO [Internet]. [cited 2019 Mar 13]. Available from: https://apps. who.int/iris/bitstream/handle/10665/249155/9789241511216-eng.pdf; jsessionid=7E8D1C6CE6506C40F497441F97A6863C?sequence $=1$

25. Indian Nursing Council, Official indian nursing council website, Government India, Establish Uniforms Standards, Training Nurses, Midwives, Health Visitors [Internet]. [cited 2019 Nov 7]. Available from: http://www.indiannursingcouncil.org/nursing-programs.asp?show=progtype

26. Bhate-Deosthali P, Khatri R, Wagle S. Poor standards of care in small, private hospitals in Maharashtra, India: implications for public-private partnerships for maternity care. Reproductive Health Matters. 2011 Jan 1;19(37):32-41.

27. Nagpal J, Sachdeva A, Dhar RS, Bhargava VL, Bhartia A. Widespread nonadherence to evidence-based maternity care guidelines: a population-based cluster randomised household survey. BJOG Int J Obstet Gynaecol. 2015; 122(2):238-47

28. Sharma G, Powell-Jackson T, Haldar K, Bradley J, Filippi V. Quality of routine essential care during childbirth: clinical observations of uncomplicated births in Uttar Pradesh. India Bull World Health Organ. 2017 Jun 1;95(6):419-29. 
29. Rosenthal G, Newbrander W. Public policy and private sector provision of health services. Int J Health Plann Manag. 1996;11(3):203-16.

30. Kujawski SA, Leslie HH, Prabhakaran D, Singh K, Kruk ME. Reasons for low utilisation of public facilities among households with hypertension: analysis of a population-based survey in India. BMJ Glob Health. 2018 Dec 1;3(6):e001002.

31. Composition and distribution of the health workforce in India: estimates based on data from the National Sample Survey 2019. Available from: http://www.rguhs.ac.in/scroll2018/skill/WHOSouth-

EastAsiaJPublicHealth52133-1621862_043018.pdf [Internet]. [cited Feb 14]

32. Strained mercy : The quality of medical care in Delhi [Internet]. ResearchGate. [cited 2019 Feb 14]. Available from: https://www. researchgate.net/publication/23722880_Strained_mercy_The_quality_of_ medical_care_in_Delhi

33. Vora DKS. Mavalankar DV. Quality of Reproductive and Child Health Care in the Private Sector in India: Issues and Options. 2012;3(8):6.

34. FOGSI Clinical Standards for Accreditation to Ensure Safe Delivery The Federation of Obstetric \& Gynecological Societies of India [Internet]. [cited 2019 Feb 14]. Available from: https://www.fogsi.org/fogsi-clinical-standardsfor-accreditation-to-ensure-safe-delivery/

35. Miller S, Abalos E, Chamillard M, Ciapponi A, Colaci D, Comandé D, et al. Beyond too little, too late and too much, too soon: a pathway towards evidence-based, respectful maternity care worldwide. Lancet. 2016 Oct; 388(10056):2176-92.

36. Bohren MA, Vogel JP, Hunter EC, Lutsiv O, Makh SK, Souza JP, et al. The Mistreatment of Women during Childbirth in Health Facilities Globally: A Mixed-Methods Systematic Review. PLoS Med Internet. 2015 Jun;12(6) Available from: https://www.ncbi.nlm.nih.gov/pmc/articles/PMC4488322/30 [cited 2019 Feb 14].

37. The Mothers on Respect (MOR) index: measuring quality, safety, and human rights in childbirth - ScienceDirect [Internet]. [cited 2019 Feb 14]. Available from: https://www.sciencedirect.com/science/article/pii/S2352827317300174

38. Declercq ER, Sakala C, Corry MP, Applebaum S, Herrlich A. Report of the Third National U.S. Survey of Women's Childbearing Experiences. 94.

39. 'I felt as though I'd been in Jail': Women's experiences of maternity care during labour, delivery and the immediate postpartum [Internet]. ResearchGate. [cited 2019 Feb 14]. Available from: https:// www.researchgate.net/publication/236010785_'I_felt_as_though_I'd_ been_in_Jail'_Women's_experiences_of_maternity_care_during_ labour_delivery_and_the_immediate_postpartum

40. Ishola F, Owolabi O, Filippi V. Disrespect and abuse of women during childbirth in Nigeria: A systematic review. PLoS One Internet. 2017 Mar 21 [cited 2019 Feb 14];12(3). Available from: https://www.ncbi.nlm.nih.gov/ pmc/articles/PMC5360318/

41. Narratives of distress about birth in South African public maternity settings: A qualitative study [Internet]. ResearchGate 2019. Available from: https://www. researchgate.net/publication/259881177_Narratives_of_distress_about_birth_ in_South_African_public_maternity_settings_A_qualitative_study

42. Sheferaw ED, Mengesha TZ, Wase SB. Development of a tool to measure women's perception of respectful maternity care in public health facilities. BMC Pregnancy and Childbirth. 2016;16(1):67.

43. Warren C, Njuki R, Abuya T, Ndwiga C, Maingi G, Serwanga J, et al. Study protocol for promoting respectful maternity care initiative to assess, measure and design interventions to reduce disrespect and abuse during childbirth in Kenya. BMC Pregnancy Childbirth. 2013 Jan 24;13:21.

44. Bhat R. Characteristics of private medical practice in India: a provider perspective. Health Policy Plan. 1999 Jan 1;14(1):26-37.

45. Human Development Index (HDI) | Human Development Reports [Internet]. 2019. Available from: http://hdr.undp.org/en/content/human-developmentindex-hdi

46. National Family Health Survey - 4 (2015 - 16) State Fact Sheet - Jharkhand Internet 2019. Available from: http://rchiips.org/nfhs/pdf/NFHS4/JH_ FactSheet.pdf

47. National Family Health Survey 4 (2015 -16) State Fact Sheet - Maharashtra Internet 2019. Available from: http://rchiips.org/nfhs/pdf/NFHS4/MH_ FactSheet.pdf

48. National Family Health Survey 4201516 State Fact Sheet - Uttar Pradesh Internet 2019. Available from: http://rchiips.org/nfhs/pdf/NFHS4/UP_ FactSheet.pdf

49. Guanche Garcell H, Villanueva Arias A, Ramírez Miranda F, Rubiera Jimenez R, Alfonso Serrano RN. Direct observation of hand hygiene can show differences in staff compliance: do we need to evaluate the accuracy for patient safety? Qatar Medical Journal. 2017;2017(2):1.

\section{Publisher's Note}

Springer Nature remains neutral with regard to jurisdictional claims in published maps and institutional affiliations.
Ready to submit your research? Choose BMC and benefit from:

- fast, convenient online submission

- thorough peer review by experienced researchers in your field

- rapid publication on acceptance

- support for research data, including large and complex data types

- gold Open Access which fosters wider collaboration and increased citations

- maximum visibility for your research: over $100 \mathrm{M}$ website views per year

At BMC, research is always in progress.

Learn more biomedcentral.com/submissions 